\title{
Does the South Atlantic Anomaly influence the ionospheric Sq current system? Inferences from analysis of ground-based magnetic data
}

\author{
Stephan Koch $^{*}$ and Alexey Kuvshinov
}

\begin{abstract}
We study if and how the South Atlantic Anomaly influences the ionospheric solar quiet (Sq) current system. Geomagnetically quiet days are processed for the years 1990 and 2011, and the Sq foci tracks are analyzed. The two datasets allow to investigate the influence of the observatory network and the solar activity on the Sq source determination. The computed tracks result in pronounced bands in the northern and southern hemisphere, which seem to neither follow the geographic nor the geomagnetic or dip equator. Remarkably, we observe a distinct scattering of the tracks over the South Atlantic Anomaly. This systematic scattering is due to a larger shift of the southern hemisphere focus northwards during the northern summer solstice and southwards during the southern summer solstice. The physical mechanism of this systematic effect remains unclear. The longitudinal variations of the $\mathrm{Sq}$ foci are believed to have their origin from an influence of non-migrating tides as reported in recent studies and the anomalous weak amplitude of the geomagnetic main field over the South Atlantic Anomaly.
\end{abstract}

Keywords: Geomagnetic daily variation; South Atlantic Anomaly; lonospheric Sq current system

\section{Background}

As a prelude to upcoming electromagnetic (EM) induction studies to determine the three-dimensional (3-D) conductivity structure of the Earth's upper mantle using the solar quiet $(\mathrm{Sq})$ geomagnetic data, it is important to have a clear understanding of the Sq current system variability with respect to local and universal times, day, season, and longitude. A vast literature exists which addresses various aspects of this problem (Fatkullin and Feldstein 1965; Hasegawa 1960; Matsushita and Maeda 1965; Pedatella et al. 2011; Stening 1971; Stening et al. 2007; Stening and Winch 2013; Takeda 1999, 2002, among others). In this paper, we revisit the problem by looking closely at the longitudinal behavior of the Sq foci tracks with the question in mind whether the South Atlantic Anomaly (SAA) influences the Sq current system. The Sq current system is flowing at a $110-\mathrm{km}$ altitude in the thin ionospheric E-layer and has a double vortex structure,

\footnotetext{
*Correspondence: stephan.a.koch@googlemail.com

Institute of Geophysics, ETH Zürich, Sonneggstrasse 5, 8092 Zürich, Switzerland
}

with an anticlockwise (clockwise) whorl in the northern (southern) hemisphere. It is driven by atmospheric tides in the ambient magnetic field of the Earth. These tides are in their turn produced by solar heating of the atmosphere on the sunlit side of the Earth. The interested reader is referred to (Campbell 1989; Olsen 1997; Richmond 1995) for details on the physics behind this current system. The Sq current system is stationary in the Earth-Sun line due to its solar origin with the Earth rotating underneath it. Because of this rotation, one can expect a modulation of Sq by the Earth's main magnetic field, with its most striking mid-latitude feature being the SAA. The SAA describes a low intensity magnetic field area, which spans from east of Africa over the Atlantic Ocean to South America. The SAA is of great interest to the scientific community as well as to the public because high-intensity solar corpuscular radiation can penetrate the Earth's orbit in the SAA region due to the weak main magnetic field. Such penetration can affect or harm the electronic systems of man-made devices such as satellites (Heirtzler 2002).

\section{是 Springer}

(c) 2015 Koch and Kuvshinov; licensee Springer. This is an Open Access article distributed under the terms of the Creative Commons Attribution License (http://creativecommons.org/licenses/by/4.0), which permits unrestricted use, distribution, and reproduction in any medium, provided the original work is properly credited. 


\section{Methods}

In this section, we introduce the used datasets. We then briefly discuss the methodology on Sq source determination and the computation and analysis of the Sq foci tracks.

\section{Data}

The determination of the Sq current system is based on the analysis of data from the global geomagnetic observatory network. To determine the Sq current system from ground-based data, a regular distribution of the observatory sites is desired; however, it is well known that the global network is over-represented by observatories in the northern hemisphere with a distinct concentration in Europe. Figure 1 shows the locations of the observatories from the Intermagnet network in the years of 1990 and 2011 alongside with additional observatories which are not part of the Intermagnet network. To investigate the robustness of the Sq source determination with respect to the irregular observatory distribution, we exploit two datasets.

Dataset 1 comprises the observatory data recorded during the Australian Wide Array of Geomagnetic Stations (AWAGS) project in addition to the global Intermagnet data. Within the AWAGS project, all three components of the geomagnetic field were measured with a sampling interval of 1 min between November 1989 and December 1990 using 53 portable vector magnetometers, from hereon referred to as year 1990 since the majority of the data was recorded in 1990. The instruments were deployed over the Australian mainland with an average site spacing of $275 \mathrm{~km}$ (Chamalaun and Barton 1993). Top plots in Figure 1 shows the locations of the Intermagnet observatories (left) and the AWAGS sites (right). Dataset 2 comprises Intermagnet observatory data from the year 2011. Location of the observatories for this year
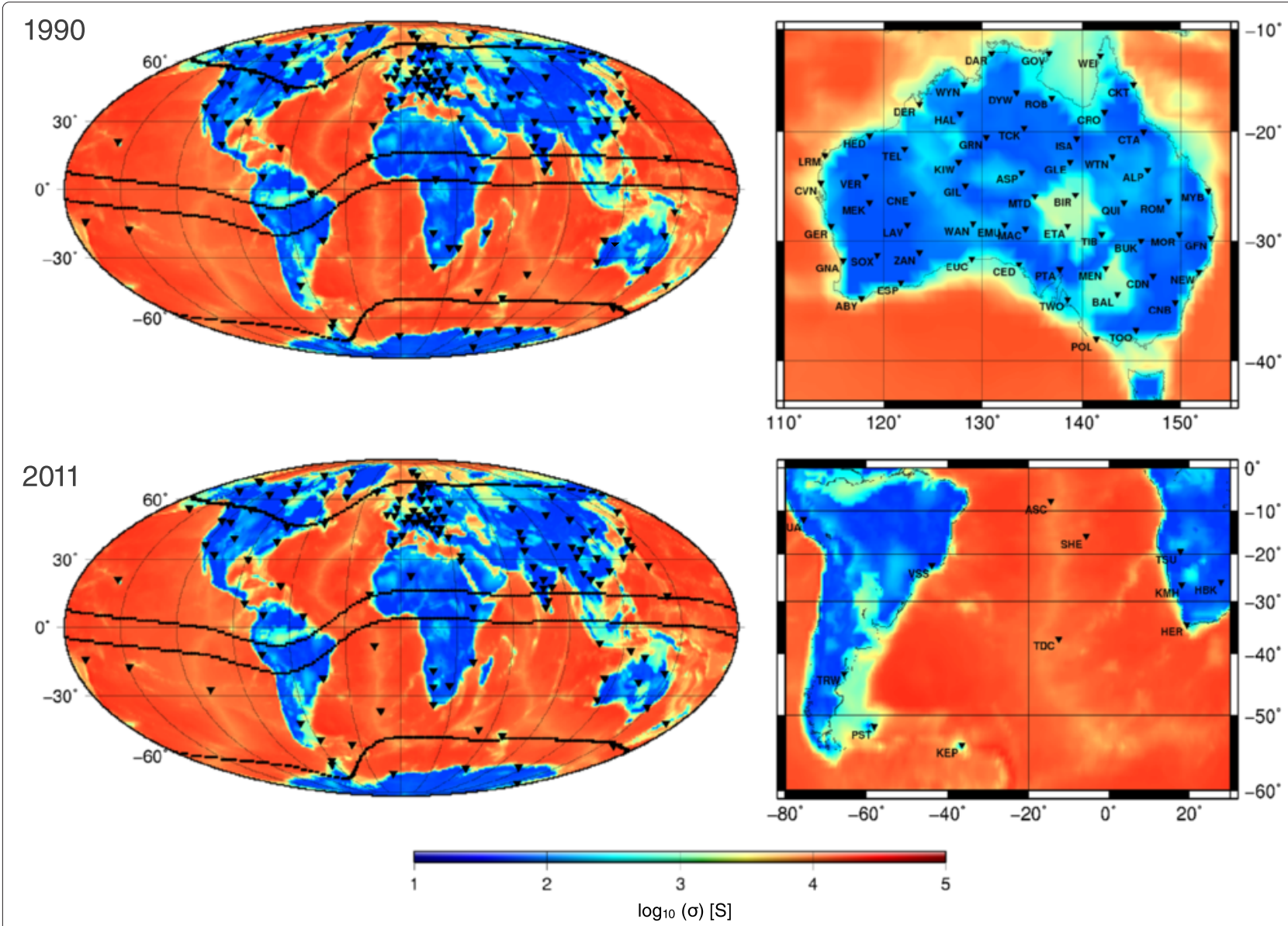

Figure 1 Location of observatory sites for the years 1990 and 2011 . The observatories (black triangles) are plotted on top of the surface shel conductance map of (Manoj et al. 2006), which is used in the S3D method to correct for the ocean effect. Black lines show the minimum and maximum dip latitude $\left(+6^{\circ}\right.$ and $+60^{\circ}$, and $-6^{\circ}$ and $\left.-60^{\circ}\right)$ in between which the mid-latitude observatories are located that were used to determine Sq current system. Top: year 1990 global map (left) with regional map of the AWAGS network (right). Bottom: year $2011 \mathrm{global}$ map (left) with regional map of the South Atlantic (right). 
are shown in the bottom plots of Figure 1. The left plot depicts their distribution on a global scale and the right plot demonstrates the observatories in the SAA region.

Dataset 1 allows to balance the Intermagnet network, which has a cluster in the European region, with the AWAGS observation sites in order to investigate the influence of the observatory distribution on the Sq source determination. dataset 2 , with observatories directly in the region of the SAA - which have not yet been installed in 1990 - allows to investigate whether additional data from the region of interest influences the results. Further, dataset 1 was recorded during a solar cycle maximum and dataset 2 during a solar cycle minimum. This allows for investigating the dependence of the $\mathrm{Sq}$ foci tracks on the solar activity.

Bearing in mind the spatial irregularity of Intermagnet data, it is strongly desirable to analyze the signals captured during time spans when the source has a spatial structure as simple as possible. The common consensus is that the spatially simplest Sq source geometry is observed during geomagnetically quiet days. As a threshold to separate quiet days from active days, we use the concept of truly quiet days, which is based on the geomagnetic $a a$-index (Mayaud 1973). The $a a$-index uses data from two nearly antipodal observatories, which are nowadays Hartland (HAD) observatory in England and the Canberra (CNB) observatory in Australia. With these two stations, which are not influenced by the auroral zone and are well balanced in the north-south as well as in the east-west directions, this geomagnetic index is sensitive to the daynight change of the Sq current system. The $a a$-index is computed in nanotesla (nT) and gives an absolute value for the magnetic activity. Following (Mayaud 1973), we characterize the day as truly quiet if $a a<20 \mathrm{nT}$ over $48 \mathrm{~h}$, centered on 12:00 UTC and $0.00^{\circ} \mathrm{E}$. This criterion assures that the actual Sq day of interest is not influenced by an enhanced geomagnetic activity $12 \mathrm{~h}$ before and after the Sq day of interest.

Using this as threshold, we compute the Sq foci tracks of 39 truly quiet Sq days in dataset 1 and 129 truly quiet Sq days in dataset 2 (Table 1). The time series of the three components of the magnetic field at each observation site for the selected days are then Fourier transformed, and the corresponding spectra for six time harmonics are estimated. These spectra serve as input data for the source determination.

\section{Sq source determination}

To determine the Sq source, we exploit the S3D method presented in (Koch and Kuvshinov 2013). It is an attractive alternative to the classic potential method of (Gauss 1838) as used for example by (Schmucker 1999). The potential method is not capable of dealing with a 3-D conductivity model as a priori information, which is of particular
Table 1 Summary of Sq days and the resulting median latitudes with respect to seasons and region

\begin{tabular}{llc}
\hline & \multicolumn{1}{c}{ SAA } & AUS \\
\hline Dataset 1 (1990) & & \\
NS (16) & $-27 \pm 5.9(34 \pm 5.7)$ & $-25 \pm 5.9(33 \pm 5.7)$ \\
EQ (7) & $-35 \pm 5.7(33 \pm 3.7)$ & $-25 \pm 5.7(29 \pm 3.7)$ \\
SS (16) & $-40 \pm 5.1(31 \pm 2.9)$ & $-29 \pm 5.1(31 \pm 2.9)$ \\
Dataset 2 (2011) & & \\
NS (25) & $-30 \pm 5.8(36 \pm 3.4)$ & $-25 \pm 5.8(31 \pm 3.4)$ \\
EQ (71) & $-36 \pm 6.6(35 \pm 5.4)$ & $-26 \pm 6.6(30 \pm 5.4)$ \\
SS (23) & $-41 \pm 5.2(30 \pm 4.5)$ & $-27 \pm 5.2(31 \pm 4.5)$ \\
\hline
\end{tabular}

The days for the two datasets are grouped into three sub-categories: NS stands for northern summer days, SS for southern summer days and EQ for the equinoctial transition days. The number in brackets behind the season represents the number of truly quiet days in the sub category. We computed the latitudes over two longitudinal sectors for the northern and southern hemisphere. The sector SAA stands for $-15^{\circ}$ longitude and AUS for the Australian sector at $135^{\circ}$ longitude. The numbers represent the seasonal median \pm the maximum standard deviation of the day-to-day tracks in the respective sub-category. Figures without brackets stand for the southern hemisphere tracks, figures with brackets and italicized stand for the northern hemisphere tracks. We observe a significant scatter of over $10^{\circ}$ in the SAA for the southern hemisphere tracks.

importance to account for the ocean effect (Kuvshinov 2008). The reader is referred to the explanation of the S3D method in (Koch and Kuvshinov 2013) for further details. The Sq source is represented by a specific set of $11 \mathrm{SH}$ coefficients for the 24-h time harmonic and by sets of 12 $\mathrm{SH}$ coefficients for the rest of the five time harmonics (12, $8,6,4.8,4 \mathrm{~h}$ ), as suggested by (Schmucker 1999). It is noted here that for the Sq source determination, we use only mid-latitude observatories in between $\pm 6^{\circ}$ and $\pm 60^{\circ}$ dip latitude to avoid effects from polar and equatorial electrojets.

\section{Analysis of Sq foci tracks}

We investigate the longitudinal as well as the day-to-day and seasonal variability of the Sq current system. We consider the positions of the Sq foci as proxy for the variability. To estimate the positions of the northern and southern Sq foci for each hour and each day, we first synthesize the Sq current system in a form of the current function on a $1^{\circ} \times 1^{\circ}$ regular grid, assigning the current system to the surface of the Earth $(a=6371 \mathrm{~km})$ :

$$
\boldsymbol{\Psi}(\vec{r}, t)=\operatorname{Re}\left(\frac{a}{\mu_{0}} \sum_{p=1}^{6} \sum_{l, k} \frac{2 l+1}{l+1} \epsilon_{l}^{k}\left(\omega_{p}\right) Y_{l}^{k}(\theta, \phi) e^{i \omega_{p} t}\right) .
$$

Here, $Y_{k}^{l}(\theta, \phi)$ is the spherical harmonic of degree $k$ and order $l, \mu_{0}$ is the magnetic permeability of free space, $\vec{r}=(a, \theta, \phi)$ with $\theta$ and $\phi$ designating geographic colatitude; and longitude, $\sum_{l, k}$ is a short-hand expression for the double sum over $k$ and $l$, and $\omega_{p}$ is the angular 
frequency. Figure 2 shows an example of the synthesized current function for six time instances on the day 199005-15. We then define the positions of the northern and the southern Sq foci for each hour of the day as the position where the value of the synthesized current function $\Psi$ reaches the extrema for the respective hour and respective geomagnetic hemisphere (divided along the dip equator). We restrict the search area to day-time regions only, by computing the solar terminator of each individual day.

\section{Results and discussion}

The resulting Sq foci tracks for the two datasets are shown in Figures 3 and 4.

Sq foci tracks for dataset 1 (1990): Dataset 1 allows to investigate if the unbalanced Intermagnet network is capable of obtaining a robust determination of the Sq source by balancing it with the 53 non-permanent AWAGS stations in Australia. The left plots in Figure 3 depict the tracks for scenario 1, when only data from the Intermagnet network were used. The right plots present tracks for scenario 2, when data from the Intermagnet and AWAGS network were used. The different colors represent results for the different seasons. The red, green, and blue colors denote the results for the northern summer (May, June, July), equinoctial (February, March, April, August, September, October), and southern summer days (November, December, January), respectively (Table 1). The upper plots show the positions of the Sq foci for each day and the lower ones the median values for the different seasons. The tracks of the Sq foci for all days and all seasons and for the two scenarios manifest as two pronounced mid-latitude bands. One can see that the tracks and the computed seasonal medians neither follow the geographic equator nor the geomagnetic equator and the dip equator. By comparing the results of the two scenarios, we find that the foci tracks are independent of the observatory network which is used to determine the Sq system with respect to the standard deviation (cf. Table 1).

We observe that, overall, the northern tracks are less scattered than the southern tracks. Moreover, we find that the southern Sq tracks show large sensitivity to the seasons in the area of the SAA, where the Earth's main magnetic field is particularly weak. Indeed, we observe a scattered patch of the southern tracks, which is traced from the east of Africa to the east coast of South America. The nature of the scattering appears to be systematic with respect to the seasonal change, best seen in the visualization of the seasonal medians, due to a larger shift of the southern hemisphere focus northwards during the northern summer solstice and southwards during the southern summer solstice. Table 1 shows the seasonal median and its standard deviation over the SAA sector $\left(-15^{\circ}\right.$ longitude) and the Australian sector (AUS; $135^{\circ}$ longitude) if Intermagnet and AWAGS data were used. For dataset 1 , we find a significant maximum difference of $13^{\circ}$ in latitude between the northern summer (NS) and southern summer (SS) tracks over the SAA region and insignificant difference of $4^{\circ}$ over the Australian region, for the southern hemisphere Sq tracks.

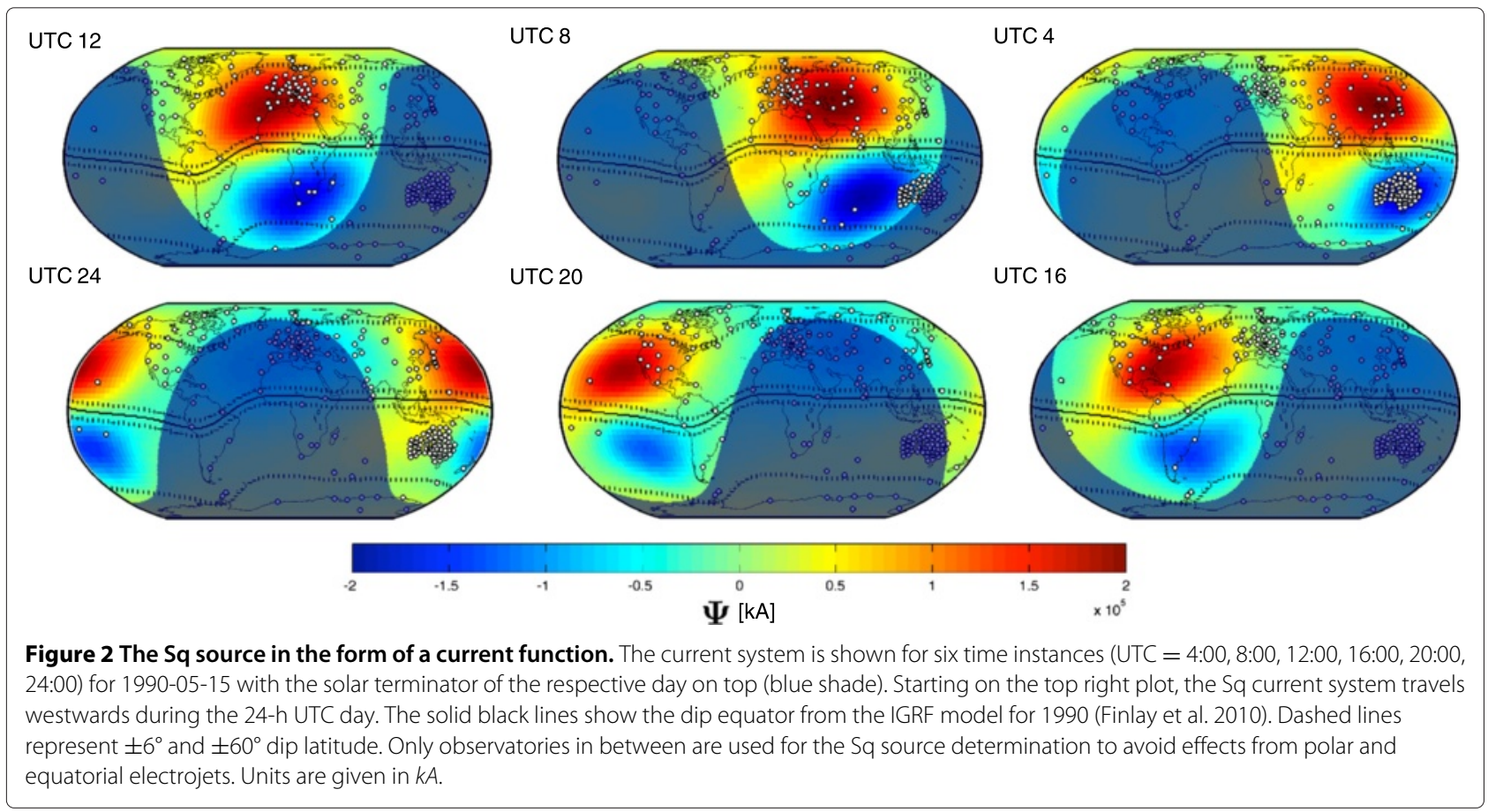




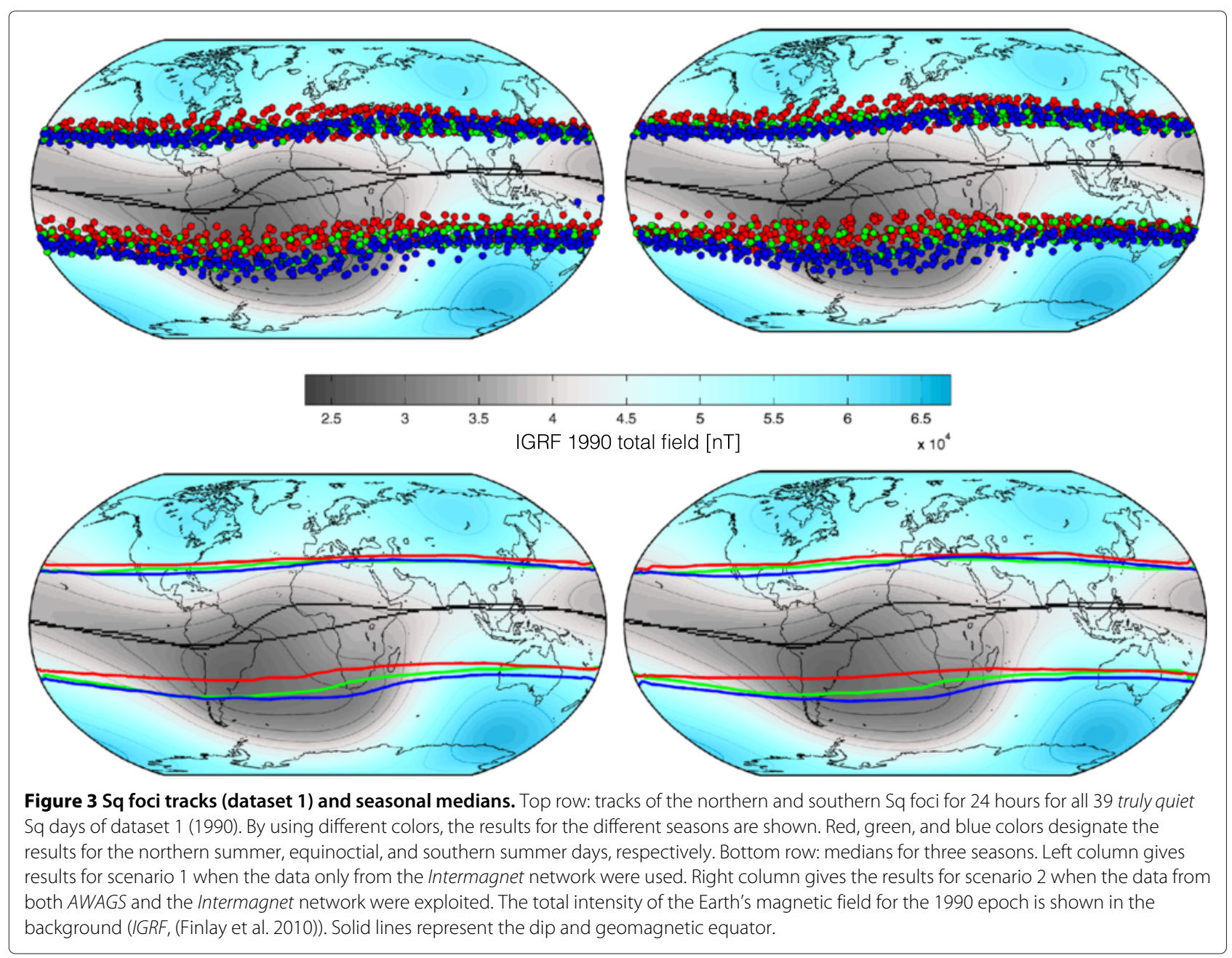

Sq foci tracks for dataset 2 (2011): One shortcoming of dataset 1 is that no observatories were installed in the direct vicinity of the SAA. Dataset 2 allows to investigate if additional observatories in the region of the SAA influence the resulting Sq foci tracks. The left plots in Figure 4 depict the tracks for scenario 1 when the data from the Intermagnet network were analyzed, but the observatories in the region of the SAA (KEP, TDC, SHE, ASC, PST) were not included. The right column gives the results for scenario 2, when all observatories were included in the dataset. We observe that the additional observatories in the vicinity of the SAA do not significantly change the resulting Sq foci tracks.

In general, the findings confirm the results of dataset 1 . Again, the tracks of the $\mathrm{Sq}$ foci for all days and all seasons and for the two scenarios manifest as two pronounced mid-latitude bands, and further, we find that the southern Sq tracks show large sensitivity to the seasons in the area of the SAA, regardless of additional observatories in the region. For dataset 2, we find a maximum difference of $11^{\circ}$ in latitude between the NS and SS tracks over the SAA region and $3^{\circ}$ over the Australian region for the southern hemisphere Sq tracks (cf. Table 1). We deduce from these observations that the systematic scattering in the vicinity of the SAA is a robust feature. Previous studies on longitudinal and seasonal variations of Sq have shown variations not only at SAA longitudes but also at other longitude sectors (Fatkullin and Feldstein 1965; Hasegawa 1960; Matsushita and Maeda 1965; Pedatella et al. 2011; Stening 1971; Stening et al. 2007; Stening and Winch 2013; 1999, 2002) among others A direct comparison with these studies however appeared to be inconclusive due to different analysis methods and data sets.

The physical mechanism of the systematic scattering of the Sq foci tracks over the SAA remains unclear. As reported in recent studies, the longitudinal variations of Sq have their origin at least partly from an influence of non-migrating tides (e.g., Lieberman et al. 2013). Further, the ionospheric gyrofrequencies are proportional to the background magnetic field $\mathbf{B}$, so the ionospheric conductivities decrease with increasing B (e.g., Richmond 1995, Stening and Winch 2013). The SAA represents an area of 


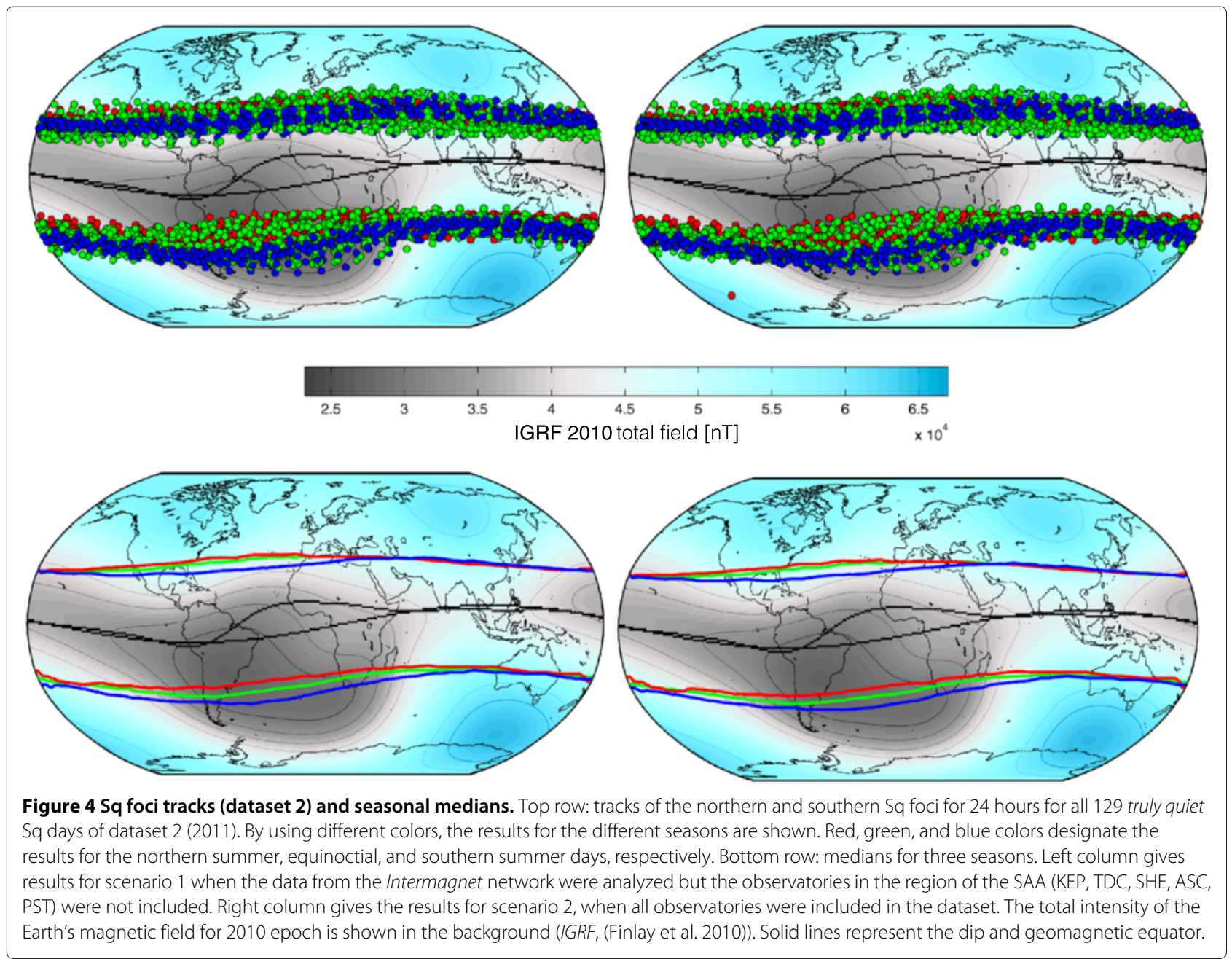

an anomalous weak geomagnetic field strength; hence, a combination of these processes is believed to influence the Sq foci tracks in the observed way. Numerical modeling studies could help to better understand the physical mechanism of the observed systematic Sq foci shift. Concerning the solar activity as a possible source for the variability of the Sq source system, we observe no influence since there is no significant difference between the results for datasets 1 and 2 in Table 1.

\section{Conclusions}

We have analyzed the Sq current system in terms of the Sq foci track variability with respect to longitude, day, season, and solar activity. The computed tracks result in pronounced mid-latitude bands in the northern and southern hemisphere. The computed Sq tracks seem to neither follow the geographic nor the geomagnetic or dip equators. We observe a pronounced scattering of the tracks over the SAA. Remarkably, the scattering appears to be very robust, irrespective of the dataset used. This systematic scattering manifests as a large shift of the southern hemisphere focus northwards during northern summer and southwards during the southern solstice. The shift of the southern Sq focus tracks with respect to the seasons is clearly evident. The physical mechanism of this systematic effect remains unclear. The longitudinal variations of the Sq foci are believed to have their origin from an influence of non-migrating tides as reported in recent studies and the anomalous weak amplitude of the geomagnetic main field over the SAA.

\section{Competing interests}

The authors declare that they have no competing interests.

\section{Authors' contributions}

SK initiated the study and performed the Sq foci track analysis. AK provided the 3-D modeling code and assisted in the scientific work. Both authors contributed to the draft, read, and approved the final manuscript.

\section{Acknowledgements}

The authors wish to thank Stewart Greenhalgh, Christoph Püthe, Nils Olsen and one anonymous reviewer who helped to improve the quality and clarity of this paper. This work was supported by SNF grant No. 2000021-121837/1. The results presented in this study are based on data collected at magnetic observatories. We thank the various national institutes which support them and Intermagnet for promoting high standards of magnetic observatory 
practice. We thank Charlie Barton, Francois Chamalaun, and the Geoscience Australia Geomagnetism Project for providing the AWAGS data set and the Helmholtz Centre Potsdam and GFZ (German Research Centre for

Geosciences) for providing St. Helena observatory data.

\section{Received: 14 May 2014 Accepted: 11 December 2014}

Published online: 22 January 2015

\section{References}

Campbell W (1989) The regular geomagnetic field variations during solar quiet conditions. Geomagnetism Vol. 3. Elsevier, New York

Chamalaun FH, Barton CE (1993) Electromagnetic induction in the Australian crust: results from the Australia-wide array of geomagnetic stations. Explor Geophys 24:179-186

Fatkullin MN, Feldstein YI (1965) Quiet solar-diurnal variations during the IGY. III. Main characteristics of the planetary distribution of Sq variations at middle and low latitudes. Geomagn Aeron 5:667-674

Finlay CC, Maus S, Beggan CD, Bondar TN, Chambodut A, Chernova TA, Chulliat A, Golovkov VP, Hamilton B, Hamoudi M, Holme R, Hulot G, Kuang W, Langlais B, Lesur V, Lowes FJ, Lühr H, Macmillan S, Mandea M, McLean S, Manoj C, Menvielle M, Michaelis I, Olsen N, Rauberg J, Rother M, Sabaka TJ,

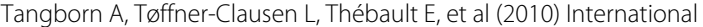
geomagnetic reference field: the eleventh generation. Geophys J Int 183(3):1216-1230

Gauss CF (1838). Allgemeine Theorie des Erdmagnetismus. Resultate aus der Beobachtung des Magnetischen Vereins Im Jahre 1838, Translated by Sabine, E. and Taylor, R. vol. 2, Scientific Memoirs Selected from the Transactions of Foreign Academies and Learned Societies and from Foreign Journals. J. and R. E. Taylor Pub., London, pp 184-251

Hasegawa M (1960) On the position of the focus of the geomagnetic Sq current system. J Geophys Res 65(5):1437-1447

Heirtzler JR (2002) The future of the South Atlantic Anomaly and implications for radiation damage in space. J Atmos Sol-Terr Phys 64(16):1701-1708

Koch S, Kuvshinov A (2013) Global 3-D EM inversion of Sq variations based on simultaneous source and conductivity determination: concept validation and resolution studies. Geophys J Int 195:98-116

Kuvshinov A (2008) 3-D global induction in the oceans and solid Earth: recent progress in modeling magnetic and electric fields from sources of magnetospheric, ionospheric and oceanic origin. Surv Geophys 29(2):139-186

Lieberman RS, Oberheide J, Talaat ER (2013) Nonmigrating diurnal tides observed in global thermospheric winds. J Geophys Res 118:7384-7397

Matsushita S, Maeda H (1965) On the geomagnetic solar quiet daily variation field during the IGY. J Geophys Res 70(11):2535-2558

Manoj C, Kuvshinov A, Maus S, Lühr H (2006) Ocean circulation generated magnetic signals. Earth Planets Space 58:429-439

Mayaud PN (1973) A hundred years series of geomagnetic data 1868-1978. IAGA Bulletin 33:255

Olsen N (1997) Geomagnetic tides and related phenomena. In: Zuern WH, Wenzel HG (eds). Tidal Phenomena. Springer, Berlin. pp 261-274

Pedatella NM, Forbes JM, Richmond AD (2011) Seasonal and longitudinal variations of the solar quiet (Sq) current system during solar minimum determined by CHAMP satellite magnetic field observations. J Geophys Res 116(A4):04317

Richmond AD (1995) lonospheric electrodynamics. In: Volland H (ed). Handbook of atmospheric electrodynamics. CRC Press, Boca Raton. pp 249-290

Schmucker U (1999) A spherical harmonic analysis of solar daily variations in the years 1964-1965: response estimates and source fields for global induction-I. Methods. Geophys J Int 136:439-454

Stening RJ (1971) Longitude and seasonal variations of the Sq current system. Radio Sci 6(2):133-137

Stening R, Reztsova T, Huyminh L (2007) Variation of Sq focus latitudes in the Australian/Pacific region during a quiet sun year. J Atmos Sol-Terr Phys 69:734-740
Stening RJ, Winch DE (2013) The ionospheric Sq current system obtained by spherical harmonic analysis. J Geophys Res 118:1288-1297

Takeda M (1999) Time variation of global geomagnetic Sq field in 1964 and 1980. J Atmos Sol-Terr Phys 61:765-774

Takeda, M (2002) Features of global geomagnetic Sq field from 1980 to 1990 J Geophys Res 107(A9):4-148

\section{Submit your manuscript to a SpringerOpen ${ }^{\circ}$ journal and benefit from:}

- Convenient online submission

- Rigorous peer review

- Immediate publication on acceptance

- Open access: articles freely available online

- High visibility within the field

- Retaining the copyright to your article

Submit your next manuscript at $>$ springeropen.com 